\title{
Evaluating environmental tobacco smoke exposure in a group of Turkish primary school students and developing intervention methods for prevention
}

\author{
Hasan C Ekerbicer*1, Mustafa Celik², Ekrem Guler ${ }^{3}$, Mehmet Davutoglu ${ }^{3}$ and \\ Metin Kilinc ${ }^{4}$
}

Address: ${ }^{1}$ Department of Public Health, Faculty of Medicine, Kahramanmaras Sutcu Imam University, Kahramanmaras, Turkey, ${ }^{2}$ Department of Family Medicine, Faculty of Medicine, Kahramanmaras Sutcu Imam University, Kahramanmaras, Turkey, ${ }^{3}$ Department of Pediatrics, Faculty of Medicine, Kahramanmaras Sutcu Imam University, Kahramanmaras, Turkey and ${ }^{4}$ Department of Biochemistry, Faculty of Medicine, Kahramanmaras Sutcu Imam University, Kahramanmaras, Turkey

Email: Hasan C Ekerbicer* - h_ekerbicer@yahoo.com; Mustafa Celik - drmcelik@gmail.com; Ekrem Guler - ekremguler@hotmail.com; Mehmet Davutoglu - drmdavutoglu@hotmail.com; Metin Kilinc - kilincmtr@yahoo.com

* Corresponding author

Published: 10 August 2007

BMC Public Health 2007, 7:202 doi:10.1 186/147/-2458-7-202

This article is available from: http://www.biomedcentral.com/147I-2458/7/202

(c) 2007 Ekerbicer et al; licensee BioMed Central Ltd.

This is an Open Access article distributed under the terms of the Creative Commons Attribution License (http://creativecommons.org/licenses/by/2.0), which permits unrestricted use, distribution, and reproduction in any medium, provided the original work is properly cited.

\begin{abstract}
Background: In countries like Turkey where smoking is highly prevalent, children's exposure to tobacco smoke is an important public health problem. The goals of this study were to determine the self-reported environmental tobacco smoke exposure status of primary school students in grades 3 to 5, to verify self-reported exposure levels with data provided from a biomarker of exposure, and to develop methods for preventing school children from passive smoking.
\end{abstract}

Methods: The study was conducted on 347 primary school students by using a standard questionnaire and urinary cotinine tests. Children with verified ETS exposure were randomly assigned to 2 intervention groups. Two phone interviews were conducted with the parents of the first group regarding their children's passive smoking status and its possible consequences. On the other hand, a brief note concerning urinary cotinine test result was sent to parents of the second group. Nine months after the initial urinary cotinine tests, measurements were repeated in both groups.

Results: According to questionnaire data, $59.9 \%$ of the study group (208 of 347) were exposed to ETS. Urinary cotinine measurements of children were highly consistent with the self-reported exposure levels $(\mathrm{P}<0.00 \mathrm{I})$. Two different intervention methods were applied to parents of the exposed children. Control tests suggested a remarkable reduction in the proportion of those children demonstrating a recent exposure to ETS in both groups. Proportions of children with urinary cotinine concentrations I0 ng/ml or lower were $79.5 \%$ in Group I and $74.2 \%$ in Group II (P $>0.05$ ).

Conclusion: Self-reported ETS exposure was found to be pretty accurate in the 9-II age group when checked with urinary cotinine tests. Only informing parents that their childrens' ETS exposure were confirmed by a laboratory test seems to be very promising in preventing children from ETS. 


\section{Background}

Exposure to ETS, also known as passive smoking, is a wellknown health hazard in children. ETS is a real and substantial threat to child health, causing suffering and death throughout the world. The World Health Organization (WHO) has reported that almost half of the children in the world (nearly 700 million) are exposed to cigarette smoke and the majority of this exposure takes place at home $[1,2]$.

The public health consequences of ETS exposure are enormous. ETS exposure increases children's risk of respiratory tract infections, otitis media, asthma, allergic disorder and the sudden infant death syndrome $[3,4]$.

Most smokers are of child bearing age, leading to as many as $50 \%$ of children exposed in their homes [1,5-7]. Thus, reduction of ETS in infants and children is an important public health goal.

The WHO recommended legislation and education to protect children from ETS exposure [1]. However, few studies have demonstrated efficacious interventions. Obviously, getting smokers to quit smoking should protect children from ETS exposure [8]. However, Wahlgren and colleagues found that $67 \%$ of parents were unable to quit or reduce their asthmatic child's ETS exposure after physician advice [9]. Thus, something more than advice to quit is needed to achieve adequate protection.

The most important measures are restrictive legislation and control of price [10-12]. In addition, communication methods that target maternal behavior change might be relevant. However various studies can be found in the medical literature that show communication and counselling methods might be effective on maternal smoking behavior [13-16]. In these studies, the communication methods were focused on protecting the child from tobacco smoke, regardless of whether or not the mothers smoked. Persuading the mothers to give up smoking was not a primary goal. The outcome variables in these studies were urinary cotinine level [13], self-reported smoking [13-15], pulmonary function tests [14], and air measurements (carbon monoxide) [16]. In the medical literature to date, there are only a few studies on confirmation of self-reported exposure status of 9-11 year-old school children.

In this study, our purposes were (a) to determine environmental tobacco smoke exposure levels of primary school students by measuring urinary cotinine levels, (b) to verify children's self-reported exposure levels by comparing questionnaire data with data derived from urinary cotinine tests, and (c) to develop methods for preventing school children from ETS exposure.

\section{Methods}

The study was conducted between September 2004 and September 2005 in 3 private primary schools in the city of Kahramanmaras, Turkey. Three hundred and forty-seven students in the third to fifth grades (9-11 years of age) of these schools were included into the study. After getting permission from Kahramanmaras City Education Department, all parents were informed about the study and their written consents were obtained.

The study was divided into two phases. In the first phase, students' exposure levels to ETS were determined by a standard questionnaire and urinary cotinine tests. The students were informed before administration of the questionnaire in their classrooms by one of the researchers and the teacher. The questionnaire consisted of 10 questions regarding demographic data (sex, grade), exposure status (number of smoking household members, number of daily exposed cigarettes, duration of exposure, outside exposure) and parents' educational status. Consistency of questionnaire data and urinary cotinine test results were also evaluated in this phase of the study. Twenty two students with (-) urinary cotinine test results contrary to their self-reports were excluded from the study. Similarly, 11 students with $(+)$ test results who had reported no ETS exposure were not included into the second phase of the study. However, parents of these 33 students were informed about possible health risks of ETS by a phone interview. In the second phase of the study, 186 students with confirmed ETS exposure were randomly assigned to two groups. Parents of the first group (Group I) were interviewed by a psychologist trained in smoking addiction. Interviews were conducted by phone on two different occasions. During the interviews with the parents, four issues were emphasized: (a) ETS exposures were selfreported by their children and confirmed by a urine test; (b) consequences of exposure to ETS in children and how to protect them; (c) possible health risks for the smoker himself/herself; (d) where they can get help in quitting smoking. Parents of the second group (Group II) were informed by a brief note with the sentence: "Your child's exposure to tobacco smoke was detected by a urine test". The notes were signed by the parents and sent back. Urinary cotinine tests were repeated nine months after the first urine tests and approximately 7 months after the counselling sessions with the parents of Group I were completed.

\section{Urine analyses}

The urine samples were collected during school time (except Mondays) before 12:00 pm without preservatives and kept at $+4{ }^{\circ} \mathrm{C}$ until use. An Immulite 2000 autoanalyser (DPC: Diagnostic Product Corporation, Los Angeles, USA. Cat no: L2KNM2) was used for nicotine metabolite measurement. Nicotine metabolite measurements were 
done by solid phase competetive chemiluminescent immunoassay and measured in $\mathrm{ng} / \mathrm{ml}$. Before testing all urine samples, 2 calibrators were used ( 4 times each). For quality control purposes, 2 control pools for 2 levels of cotinine (low and high) were used. The low control showed a total CV of $13.3 \%$ (mean 12.8 , SD $1.7 \mathrm{ng} / \mathrm{ml}$ ) and the high control showed a total CV of $6.2 \%$ (mean $47.1, \mathrm{SD} 2.9 \mathrm{ng} / \mathrm{ml}$ ). Same quality control procedures were used in the second stage of the study.

\section{Statistical analysis}

Data were expressed as number of subjects and percentages. Statistical analyses were performed by using the Pearson correlation coefficient and Chi-square test. P values $<0.05$ were considered statistically significant. All data were entered into and processed by SPSS version 11.0 for Windows statistical package (SPSS Inc., Chicago, IL).

\section{Results}

Of 347 students, 208 (59.9\%) reported ETS exposure at home. In response to the question "Which household member (or members) is smoking regularly at home?" 89 $(42.7 \%)$ of the students pointed out both parents, 80 (38.4\%) reported only their father, $26(12.7 \%)$ reported 3 or more household members, and $13(6.2 \%)$ reported only their mother. In the homes of $55.4 \%$ of the passive smoking children, two or more household members were smoking regularly. Children with self-reported ETS exposure addressed no exposure outside the house. Of these 208 students, 131 (62.9\%) were being exposed to 1-3 cigarettes per day at home and $77(36.1 \%)$ were being exposed to 4 or more. In reply to the question regarding daily duration of exposure: $128(61.5 \%)$ responded $1-2$ hours and $80(38.5 \%) 3$ or more hours. There was no significant correlation between number of cigarettes exposed to, daily duration of exposure and urinary cotinine levels ( $\mathrm{p}>0.05$ for both).

The proportion of self-reported exposure did not differ significantly between sexes, grades or parents' educational status $(\mathrm{p}>0.05)$ (Table 1).

None of the students was found to be an active smoker according to urinary cotinine test results. The highest urinary cotinine level mesured in both stages of the study was $81 \mathrm{ng} / \mathrm{ml}$. Of the 208 students with self-reported ETS exposure, $10.6 \%$ of them (22) had urinary cotinine levels $\leq 10 \mathrm{ng} / \mathrm{ml}$ while $89.4 \%$ (186) had between $11-500 \mathrm{ng} /$ $\mathrm{ml}$. These proportions were $92.1 \%$ (128) and 7.9\% (11), respectively, in 139 non-exposed students. The distribution of students according to self-reported exposure status and urinary cotinine levels are shown in Figure 1.

Urinary cotinine tests were repeated to evaluate the effectiveness of both interventions at 9 months follow-up. In
Table I: Comparison of some demographic characteristics of students according to their self-reported exposure status

\begin{tabular}{|c|c|c|c|}
\hline & \multicolumn{2}{|c|}{ Self reported exposure } & \multirow[t]{2}{*}{$P$ value } \\
\hline & Yes & No & \\
\hline \multicolumn{4}{|l|}{$\operatorname{Sex}(n=347)$} \\
\hline Male & $124(62.0 \%)$ & 76 (38.0\%) & $>0.05$ \\
\hline Female & $84(57.2 \%)$ & $63(42.8 \%)$ & \\
\hline \multicolumn{4}{|l|}{ Grade $(n=347)$} \\
\hline $3 r d$ & $66(61.7 \%)$ & 41 (38.3\%) & \\
\hline 4 th & 79 (63.2\%) & $46(36.8 \%)$ & $>0.05$ \\
\hline 5 th & $63(54.8 \%)$ & $52(45.2 \%)$ & \\
\hline \multicolumn{4}{|l|}{$\begin{array}{l}\text { Mother's education }(n= \\
\text { 336) }\end{array}$} \\
\hline Primary-Middle School & $63(57.2 \%)$ & 47 (42.8\%) & \\
\hline High School & $66(62.3 \%)$ & 40 (37.7\%) & $>0.05$ \\
\hline University and over & $78(65.0 \%)$ & $42(35.0 \%)$ & \\
\hline \multicolumn{4}{|l|}{$\begin{array}{l}\text { Father's education }(n= \\
341)\end{array}$} \\
\hline Primary-Middle School & $12(20.0 \%)$ & $8(40.0 \%)$ & \\
\hline High School & $79(64.8 \%)$ & $43(35.2 \%)$ & $>0.05$ \\
\hline University and over & 117 (58.5\%) & $83(41.5 \%)$ & \\
\hline
\end{tabular}

Group I, 74 students out of 93 (79.5\%) had urinary cotinine levels below $10 \mathrm{ng} / \mathrm{ml}$ compared to 69 out of 93 $(74.2 \%)$ in Group II. The percentages of children with urinary cotinine values equal to $10 \mathrm{ng} / \mathrm{ml}$ or less were statistically similar $(\mathrm{p}>0.05)$ in both intervention groups (Figure 2).

\section{Discussion}

In our study, 59.9\% of the children were reported ETS exposure at home. In the United States the prevalence of children living in homes with a smoker has been estimated to be $43 \%$, with state specific estimates of exposure at home ranging from $12 \%$ to $34 \%$ [5]. Thirty-five percent

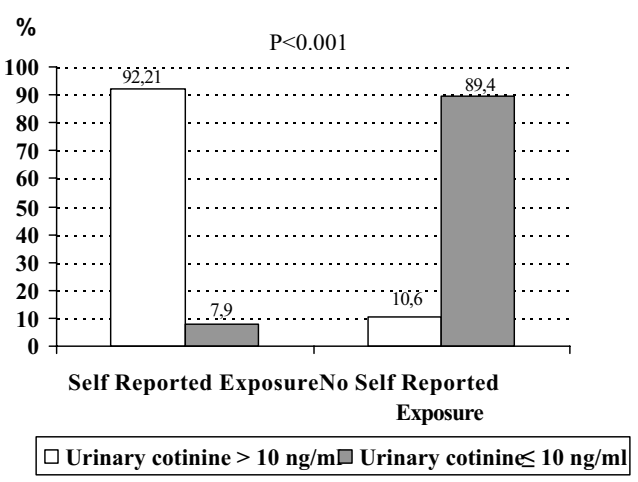

\section{Figure I}

Distribution of students according to self-reported exposure status and urinary cotinine levels $(n=347)$. 
of children in the United States live in homes in which residents or visitors smoke on a regular basis [17]. Similarly, about $43 \%$ of Australian children [18], 33\% of Canadian children [19], 41\% of British children [20], 59.2\% of the students in Mexico [21] and 89.0\% of Turkish children [22] are exposed to environmental tobacco smoke.

In the present study, $89(42.7 \%)$ of the students pointed out both parents smoking at home, while 80 (38.4\%) reported only their father, $26(12.7 \%)$ reported 3 or more household members and 13 (6.2\%) reported only their mother. In a study conducted by Celik et al. [23], it was found that $12.6 \%$ of the mothers, $49.2 \%$ of fathers, and overall in $42.2 \%$ of the families, one or more persons smoked at home.

We found that mothers with higher education levels were more likely to smoke at home, although not statistically significant. In another study conducted in Kahramanmaras, Celik et al. [23] showed that rates of homes with at least one smoking household member and rates of smoking mothers were positively correlated with the educational levels of mothers. Moreover, in a study representing whole the Turkish population, it was reported that smoking more than 10 cigarettes was most common among women with at least a high school education (45\%) [24]. The fact that studies in Western countries reveal a negative correlation between women's education levels and smoking status, unlike studies from Turkey, may be because of the conservative socio-cultural environment of the country $[25,26]$.

Socioeconomic factors also are known to be related to cotinine levels. Parental education and family income both may be indicators of the prevalence of smoking in the community in which the child lives and plays $[27,28]$. The effect of maternal smoking on child salivary cotinine level has been reported to be greater than the effect of paternal smoking in England and Wales, especially with high levels of cigarette consumption [29]. Housing characteristics have also been previously described as being associated with cotinine levels, with smaller homes predicting higher levels among smoke-exposed children [28]. In our study, the proportion of self-reported exposure did not differ significantly between sexes, grades or parents' educational status, as well as between urinary cotinine levels and number of cigarettes exposed to and the daily duration of exposure. In contrast to our study, it has been reported by 3 different studies that the number of cigarettes that parents smoke is a major determinant of salivary cotinine concentration in children $[27,28,30]$. This contradiction may be attributable to the choice of method in measuring cotinine. Consistent with our results, Smyth et al. [31] have reported that salivary cotinine was more closely related to family smoking behavior than urinary cotinine concentrations.

Most estimates of the exposure of infants and young children to tobacco smoke are based on adult reports. Selfreports have the advantage of low cost and ease of administration, but raise questions of reliability and validity. Brunekreef et al. [32] emphasize that underreporting of ETS exposure by parents of study children varies, and may depend on the instrument used, population studied, age, and symptom status, underlining the need for questionnaire validation in specific study settings. In addition to urinary cotinine tests, we used a questionnaire to assess subjects' ETS exposure levels. Besides those with 33 (9.5\%) of the students, all of the others cotinine test results were consistent with the self-reports. In interpreting our results, the age group of our subjects and the fact that they are private school students must be considered.

In our study, mean urinary cotinine levels of two intervention groups measured nine months after the initial urinary tests were similar, and in both groups, urinary cotinine levels of the majority of the students were below $10 \mathrm{ng} / \mathrm{ml}$ (Figure 2). We suggest that a brief intervention incorporating feedback of children's urinary cotinine levels via a letter would display a similar positive effect on parents' attitude on restricting smoking at home as feedback plus intensive counselling. In another study with a similar design to ours, Wakefield et al. [33] reported no significant change in smoking habits of parents between intervention (written and verbal feedback about child's urinary cotinine level) and control (usual advice about smoking) groups. Their study differed from ours in that children in their intervention group were predominantly from low-income families, and $69.5 \%$ of mothers were smoking at home. Three other studies concerning chil-

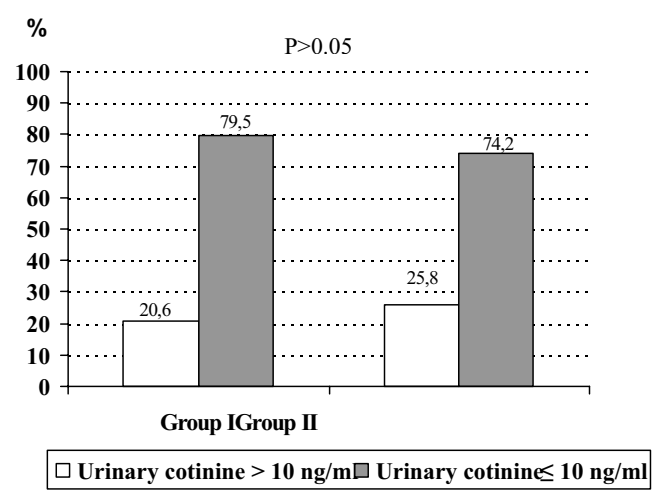

\section{Figure 2}

Comparison of two intervention groups nine months after the initial urinary tests. 
dren's exposure to ETS at home have revealed that counselling and advice, without feedback on children's urinary cotinine levels, did not change the children's exposure to ETS [27,34-36]. In this context, Hovell et al.'s study [15] is an exception, in which authors reported that an intervention involving more intensive counselling was associated with significant decreases in children's exposure to ETS. The results of this study were obtained with a group of low-income families, in which families were paid as an incentive to participate.

\section{Limitations of the study}

One of the limitations of our study is a lack of a control group made up of passive smokers, whose parents were informed about their children's self reported exposure to ETS but not informed about urinary cotinine test results. However, forming three subgroups within the passive smokers would result small sample sizes. Also, the high consistency of self reported exposure and urinary cotinine concentrations, and the assumption that the parents belonging to a high socioeconomic group have at least a basic level of knowledge about the harms of ETS, encouraged us to complete the study without any further control group.

Conducting the study only in private schools in order to reach a socioeconomically homogeneous group of students makes it difficult to generalize our results to all 911 year-old students in the city or the country. However, we believe that providing data on the consciousness of a highly educated group of parents regarding ETS in a country where more than 60 percent of men smoke is of value.

Although there are more specific tests for quantitating human exposure to ETS, urinary cotinine tests were preferred due to limited funding.

\section{Conclusion}

The prevalence of passive smoking was fairly high in the study group. Self-reported ETS exposure status of 9-11 year-old students were consistent with their urinary cotinine levels. Informing parents that their children's ETS exposure was confirmed by a laboratory test had a positive effect in preventing them from home ETS exposure. Further studies with a similar design should be carried out in socio-economically different population groups. We also think that investigation of families who develop effective policies in reducing the ETS exposure of their children will be benefical. If further studies confirm our findings, carrying out urinary cotinine tests routinely in the presence of self-reported ETS exposure may be considered for this age group.

\section{Competing interests}

The author(s) declare that they have no competing interests.

\section{Authors' contributions}

HCE designed the paper, performed the analyses, and is the primary author. MC designed the paper, provided data and commented on early drafts. EG commented on early drafts. MD provided data and commented on early drafts. MK provided data and commented on early drafts. All authors read and approved the final manuscript.

\section{Acknowledgements}

Presented as a poster at $3^{\text {rd }}$ National Conference on Tobacco or Health with International Contributions, 24-26th Nov 2006, Ankara, Turkey.

The authors are grateful to Prof. Dr. Yakup Gumusalan for linguistic assistance. They also thank the school directors, the teachers, the students and their parents taking part in the study.

Grants: The study was funded by the Research Projects Direction Unit of Kahramanmaras Sutcu Imam University.

\section{References}

I. World Health Organization. Division of Noncommunicable Diseases. Tobacco Free Initiative: International Consultation on Environmental Tobacco Smoke (ETS) and Child Health, Consultation Report. Geneva, Switzerland. I I-I4 January 1999. :4 [http://www.who.int/toh].

2. World Health Organization: The Tobacco Atlas. [http:// www.who.int/tobacco/statistics/tobacco atlas/en].

3. Klonoff-Cohen HS, Edelstein SL, Lefkowitz ES, Srinivasan IP, Kaegi D, Chang JC, Wiley KJ: The effect of passive smoking and tobacco exposure through breast milk on sudden infant death syndrome. JAMA 1995, 273:795-798.

4. Difranza JR, Lew RA: Morbidity and mortality in children associated with the use of tobacco products by other people. Pediatrics 1996, 97:560-568.

5. Pirkle JL, Flegal KM, Bernert JT, Brody DJ, Etzel RA, Maurer KR: Exposure of the US population to environmental tobacco smoke. The third national health and nutrition examination survey, I988 to I99I. JAMA I996, 275: I233-I240.

6. Collaborative Group SIDRIA (Italian Studies on Respiratory Disorders in Childhood and the Environment): Parental smoking, asthma and wheezing in children and adolescents. Results of SIDRIA. Epidemiol Prev 1998, 22:146-154.

7. Lister SM, Jorm LR: Parental smoking and respiratory illnesses in Australian children aged 0-4 years: ABS 1989-90 national health survey results. Austr NZJ Public Health 1998, 22:78I-786.

8. Borland R, Mullins R, Trotter $L$, White $V$ : Trends in environmental tobacco smoke restrictions in the home in Victoria, Australia. Tobacco Control 1999, 8:266-27I.

9. Wahlgren DR, Hovell MF, Meltzer SB, Hofstetter CR, Zakarian JM: Reduction of environmental tobacco smoke exposure in asthmatic children. A 2-year follow-up. Chest 1997, I I I:8 I-88.

10. Peterson DE, Zeger SL, Remington PL, Anderson HA: The effect of state cigarette tax increases on cigarette sales, 1955 to 1988. Am J Public Health 1992, 82:94-96.

II. Givel MS, Glantz SA: Tobacco lobby political influence on US state legislatures in the 1990s. Tob Control 2001, 10:124-134.

12. Menzel P: Risk perception, addiction, and costs to others: an assessment of cigarette taxes and other anti-smoking policies. Health Care Anal 1994, 2:13-22.

13. Greenberg RA, Strecher VJ, Bauman KE, Boat BW, Fowler MG, Keyes LL, Denny FW, Chapman RS, Stedman HC, LaVange LM: Evaluation of a home-based intervention program to reduce infant passive smoking and lower respiratory illness. J Behav Med 1994, 17:273-290. 
14. Wahlgren DR, Hovell MF, Meltzer SB, Hofstetter CR, Zakarian JM: Reduction of environmental tobacco smoke exposure in asthmatic children. A 2-year follow-up. Chest 1997, I I I:8 I-88.

15. Hovell MF, Zakarian JM, Matt GE, Hofstetter CR, Bernert JT, Pirkle J: Effect of counselling mothers on their children's exposure to environmental tobacco smoke: randomised controlled trial. Br Med J 2000, 32 I:337-342.

16. Emmons KM, Hammond SK, Fava JF, Velicer WF, Evans JL, Monroe $A D$ : A randomized trial to reduce passive smoke exposure in low-income households with young children. Pediatrics 200I, I 08: 18-24.

17. Schuster MA, Franke T, Pham CB: Smoking patterns of household members and visitors in homes with children in the United States. Arch Pediatr Adolesc Med 2002, I 56: I 094-I I 00.

18. National Health and Medical Research Council: The health effects of passive smoking. Australia: NHMRC; 1997.

19. Physicians for a Smoke-Free Canada. Highlight sheet No I. Smoking in Canadian homes: Are children at risk? 1999 [http://www.smoke-free.ca/eng home/news press Jun99.htm].

20. Jarvis M, Goddard E, Higgins V, Feyerabend C, Bryant A, Cook DG: Children's exposure to passive smoking in England since the I980s: Cotinine evidence from population surveys. BMJ 2002, 321:343-345.

21. Warren CW: Tobacco use among youth: $\mathbf{A}$ cross country comparison. Tobacco Control 2002, I I:252-270.

22. Türkiye Küresel Gençlik Tütün Araştırması-2003, Sağlık Bakanlığı Madde Bağımlılığı Şube Müdürlüğü. Tütünsüz Yaşam Dergisi (Turkish Journal of Tobacco-Free Life) 2006, 2:9.

23. Celik M, Ekerbicer HC, Ergun UG, Guler E, Kaya D: Prevalence of Passive Smoking in Children and Adolescents in Kahramanmaras, Turkey. Ist Congress of the Association doctors GPIFM SouthEast Europe (A GPIFM SEE), Ohrid, I5-18 June 2006, Republic of Macedonia. Congress Book 2006:281.

24. Turkey Demographic and Health Survey 2003, Hacettepe University Institute of Population Studies, Ankara, Turkey [http://www.hips.hacettepe.edu.tr/tnsa2003eng/index.htm]

25. Braaten T, Weiderpass E, Kumle M, Lund E: Explaining the socioeconomic variation in cancer risk in the Norwegian Women and Cancer Study. Cancer Epidemiol Biomarkers Prev 2005, | 4:259|-2597. Erratum in: Cancer Epidemiol Biomarkers Prev 2006, I5: 187

26. Graham H, Der G: Patterns and predictors of tobacco consumption among women. Health Educ Res 1999, 14:61 I-618.

27. Irvine L, Crombie IK, Clark RA, Slane PW, Goodman KE, Feyerabend $C$, Cater Jl: What determines levels of passive smoking in children with asthma? Thorax 1997, 52:766-769.

28. Bakoula CG, Kafritsa YJ, Kavadias CD, Haley NJ, Matsaniotis NS: Factors modifying exposure to environmental tobacco smoke in children (Athens, Greece). Cancer Causes Control 1997, 8:73-76.

29. Cook G, Whincup PH, Jarvis MJ, Strachan DP, Papacosta O, Bryant A: Passive exposure to tobacco smoke in children aged 5-7 years: individual, family, and community factors. BMJ 1994 308:384-389.

30. Mannino DM, Caraballo R, Benowitz N, Repace J: Predictors of Cotinine Levels in US Children. Data From the Third National Health and Nutrition Examination Survey. Chest 200I, I 20:718-724.

31. Smyth A, O'Hea U, Feyerabend C, Lewis S, Smyth R: Trends in passive smoking in cystic fibrosis, 1993-1998. Pediatr Pulmonol 200|, 3 I: | 33- I37.

32. Brunekreef B, Leaderer BP, van Strien R, Oldenwening M, Smit HA, Koopman L, PIAMA study group: Using nicotine measurements and parental reports to assess indoor air: the Piama birth cohort study. Epidemiology 2000, I I:350-352.

33. Wakefield MA, Chaloupka FJ, Kaufman NJ, Orleans CT, Barker DC Ruel EE: Effect of restrictions on smoking at home, at school, and in public places on teenage smoking: Cross sectional study. BMJ 2000, 321:333-337.

34. Woodward A, Owen N, Grgurinovich N, Griffith K, Linke H: Trial of an intervention to reduce passive smoking in infancy. Pediatr Pulmonol 1987, 3:173-178.

35. Chilmonczyk BA, Palomaki GE, Knight GJ, Williams J, Haddow JF: An unsuccessful cotinine-assisted intervention strategy to reduce environmental tobacco smoke exposure during infancy. Am J Dis Childhood 1992, I46:357-360.
36. Mclntosh NA, Clark NM, Howatt W: Reducing tobacco smoke in the environment of the child with asthma: a cotinineassisted minimal-contact intervention. J Asthma 1994, 3 I:453-462.

\section{Pre-publication history}

The pre-publication history for this paper can be accessed here:

http://www.biomedcentral.com/1471-2458/7/202/pre pub

Publish with Biomed Central and every scientist can read your work free of charge

"BioMed Central will be the most significant development for disseminating the results of biomedical research in our lifetime. "

Sir Paul Nurse, Cancer Research UK

Your research papers will be:

- available free of charge to the entire biomedical community

- peer reviewed and published immediately upon acceptance

- cited in PubMed and archived on PubMed Central

- yours - you keep the copyright 